\title{
Pulp in Shop-Bought Orange Juice Has Little Effect on Flavonoid Content and Gut Bacterial Flavanone Degradation In Vitro
}

\author{
Min Hou ${ }^{1,2} \cdot$ Emilie Combet $^{1} \cdot$ Christine Ann Edwards $^{1}$ (B)
}

Published online: 21 June 2019

(C) The Author(s) 2019

\begin{abstract}
Orange juice is an important source of flavanones in the Western diet. However, little is known of the variation in flavanone content of shop-bought orange juice with pulp (OJP) or without pulp (OJ), nor the impact of pulp on the fate of flavanones in the gut. Total phenols, total flavonoids, antioxidant capacity, hesperidin and narirutin, and dietary fibre were measured in six orange juice brands sold as OJP and OJ. The inclusion of pulp had little impact on fibre content. Apart from total phenols (OJ: 208.4 \pm $10.7 \mu \mathrm{g}$ gallic acid equivalents (GAE) $\mathrm{ml}^{-1}$; OJP: $225.9 \pm 16.7 \mu \mathrm{g} \mathrm{GAE} \mathrm{ml}{ }^{-1}, P<0.05$ ), there were no differences between OJ and OJP. The fate of flavanones in OJ and OJP (Tropicana) were further compared using in vitro gastrointestinal (GI) models. After in vitro upper GI digestion, recovery of hesperidin was higher in OJ compared with OJP ( $89 \pm 6$ vs. $68 \pm 3 \%, P=0.033$ ). After $2 \mathrm{~h}$ colonic fermentation, hesperidin was 1.2 fold higher in OJP than OJ. However, after $24 \mathrm{~h}$ colonic fermentation there was no significant difference between juices in terms of hesperidin, hesperetin, narirutin, naringenin and catabolites. In conclusion, the amount of pulp included in these shop-bought orange juices had little impact on flavanone metabolism in models of the GI tract. The effects of greater amounts of orange pulp remain to be determined.
\end{abstract}

Keywords Colonic fermentation $\cdot$ Gastrointestinal digestion $\cdot$ Orange juice flavanones $\cdot$ Phenolic catabolites $\cdot$ Pulp

$\begin{array}{ll}\text { Abbreviations } \\ \text { GAE } & \begin{array}{l}\text { Gallic acid equivalents } \\ \text { GI }\end{array} \\ \text { HPLC-PDA } & \begin{array}{l}\text { High performance liquid } \\ \text { chromatography-photodiode array detector }\end{array} \\ \text { OJ } & \text { Orange juice without pulp } \\ \text { OJP } & \text { Orange juice with pulp }\end{array}$

Electronic supplementary material The online version of this article (https://doi.org/10.1007/s11130-019-00739-5) contains supplementary material, which is available to authorized users.

Christine Ann Edwards

Christine.edwards@glasgow.ac.uk

1 Human Nutrition, School of Medicine, Dentistry and Nursing, College of Medical, Veterinary \& Life Sciences University of Glasgow, New Lister Building, Glasgow Royal Infirmary, 10-16 Alexandra Parade, Glasgow G31 2ER, Scotland, UK

2 School of Public Health, College of Medicine, Shanghai Jiao Tong University, Shanghai, China

\section{Introduction}

Orange juice is widely consumed and has been associated with a range of potential health effects including antiinflammatory actions $[1,2]$, positive impact on cardiovascular risk factors [3-5], and cognitive function [6]. Orange juice is a rich source of polyphenols mainly flavanones (hesperidin and narirutin) which, along with their catabolites, may contribute substantially to the health effects of the juice. To elucidate dietary intakes for epidemiological studies and to develop nutritional advice, it is necessary to understand 1) how flavanone content varies between sources, and 2) how different formulations affect flavanone metabolism and catabolite release in the GI tract.

According to the Phenol-Explorer database [7], the content of hesperidin $(4-73 \mathrm{mg} / 100 \mathrm{ml})$ and narirutin $(2-15 \mathrm{mg} /$ $100 \mathrm{ml}$ ) in pure orange juice (blond) varies substantially. The bioavailability of flavanones also varies considerably with $0.8-16 \%$ of ingested dose excreted in urine depending on the OJ tested [8-14]. This means that most of the ingested flavanones reach the colon. In juice, flavanones are present mainly as glycosides [4], and can be absorbed into circulatory system only after deglycosylation and degradation by 
intestinal enzymes or bacteria [11, 15-17]. In the colon, the aglycones (hesperetin, naringenin) are released by bacterial $\beta$ glucosidase, $\alpha$-rhamnosidase and $\beta$-glucuronidase [18]. Clostridia, eubacteria, bifidobacteria and lactobacilli can then use ring-cleavage, decarboxylation, demethylation, and dehydroxylation [18-21] to transform flavonoids into bioavailable and bioactive phenolic acids [17].

Orange juice is now commonly marketed as smooth (no pulp) juice and juice with pulp (or 'with bits' in the UK) (OJP). The pulp is derived from the cellular tissues of the endocarp [22]. There has been suggestion from studies using juices with extra added pulp that this adds substantially to flavanone content $[23,24]$. Polyphenols closely physically associated with dietary fibre are at least partially bioavailable [25]. However, it is not clear if shop bought juices with pulp (OJP) have the same impact nor if the addition of pulp in these juices impacts on the bioaccessibility, metabolism and catabolism of the flavanones in the small and large intestine. In this study, the stability, release and degradation of flavanones were assessed in UK shop-bought juices formulated with and without pulp using in vitro models of GI digestion and colonic fermentation.

\section{Materials and Methods}

\section{Chemicals}

Full details of chemicals and standards used are in online supplementary files.

\section{Orange Juices for Analysis}

A selection six brands of OJ and OJP (Table 1; labelled 100\% freshly squeezed, not from concentrate) were purchased from local supermarkets in Glasgow, UK between April of 2013 and March of 2014. Additional details are in the supplementary file.

\section{Analysis of Fibre in OJ and OJP}

The fibre content of each orange juice was analysed by using AOAC method [26] by the commercial food testing facility at the School of Health and Life Science, Glasgow Caledonian University, Glasgow, UK.

\section{Analysis of Total Flavonoids, Total Phenols, Antioxidant Capacity}

Total flavonoids were determined in orange juices by spectrophotometric method [27]. Total phenols in orange juices and samples from in vitro GI digestion was determined by the Folin-Ciocalteau method [28]. Antioxidant capacity was determined in orange juices and samples from in vitro GI digestion using the FRAP assay [29]. See supplementary material for additional details.

\section{In Vitro Gastrointestinal Digestion Model}

Tropicana juices (OJ and OJP) were selected as a representative and popular brand in the UK for investigating in vitro digestion and fermentation of orange juice in the gut models.

Table 1 Total phenolic content ( $\mu \mathrm{g} \mathrm{GAE} \mathrm{ml}^{-1}$ ), total flavonoids ( $\mu \mathrm{g} \mathrm{QE} \mathrm{ml}{ }^{-1}$ ), antioxidant capacity $\left(\mathrm{mM} \mathrm{Fe} \mathrm{e}^{2+}\right.$ ), narirutin $(\mathrm{mg} / 100 \mathrm{ml})$, hesperidin $(\mathrm{mg} /$ $100 \mathrm{ml})$ and dietary fibre content $(\mathrm{g} / 100 \mathrm{ml})$ in orange juices

\begin{tabular}{|c|c|c|c|c|c|c|c|}
\hline Brand & Type & Total phenols & Total flavonoids & FRAP & Narirutin & Hesperidin & Dietary fibre \\
\hline \multirow[t]{2}{*}{ Tropicana } & OJ & $216.5 \pm 12.0$ & $76.8 \pm 0.5$ & $5.9 \pm 0.3$ & $4.2 \pm 0.2$ & $37.3 \pm 1.8$ & 0.1 \\
\hline & OJP & $228.4 \pm 5.9$ & $86.7 \pm 17.1$ & $6.4 \pm 0.4$ & $4.9 \pm 0.3$ & $40.5 \pm 1.6$ & 0.1 \\
\hline \multirow[t]{2}{*}{ Sainsbury's } & OJ & $213.5 \pm 2.7$ & $84.9 \pm 13.6$ & $6.0 \pm 0.1$ & $2.3 \pm 0.1$ & $34.5 \pm 0.5$ & 0.1 \\
\hline & OJP & $252.3 \pm 6.6$ & $100.2 \pm 15.0$ & $7.4 \pm 0.4$ & $3.7 \pm 0.3$ & $40 \pm 1.5$ & 0.3 \\
\hline \multirow[t]{2}{*}{ Tesco } & OJ & $220.9 \pm 1.9$ & $79.2 \pm 3.3$ & $6.3 \pm 0.5$ & $3.7 \pm 0.1$ & $38 \pm 0.8$ & 0.1 \\
\hline & OJP & $226.1 \pm 5.9$ & $78.9 \pm 7.7$ & $6.1 \pm 0.6$ & $4.1 \pm 0.1$ & $41.9 \pm 1.5$ & 0.2 \\
\hline \multirow[t]{2}{*}{ Innocent } & OJ & $197.2 \pm 9.1$ & $82.5 \pm 5.2$ & $4.6 \pm 0.3$ & $4.4 \pm 0.2$ & $30 \pm 1.2$ & 0.1 \\
\hline & OJP & $199.8 \pm 9.6$ & $81.9 \pm 3.5$ & $5.0 \pm 0.2$ & $5.3 \pm 0.1$ & $37.4 \pm 1.9$ & 0.2 \\
\hline \multirow[t]{2}{*}{ Morrison’s } & OJ & $207.8 \pm 3.2$ & $86.4 \pm 1.2$ & $5.2 \pm 0.1$ & $7.8 \pm 0.1$ & $21.5 \pm 1.0$ & 0.1 \\
\hline & OJP & $224.0 \pm 7.7$ & $101.1 \pm 7.0$ & $5.3 \pm 0.1$ & $9.6 \pm 0.9$ & $21 \pm 1.7$ & 0.2 \\
\hline \multirow[t]{2}{*}{ Waitrose } & OJ & $194.5 \pm 8.2$ & $78.6 \pm 12.9$ & $4.9 \pm 0.3$ & $2.6 \pm 0.1$ & $17.8 \pm 0.2$ & 0.3 \\
\hline & OJP & $224.6 \pm 9.1$ & $108.9 \pm 14.6$ & $5.2 \pm 0.1$ & $2.8 \pm 0.4$ & $18.5 \pm 1.3$ & 0.2 \\
\hline \multirow[t]{2}{*}{ Mean } & OJ & $208.4 \pm 10.7$ & $81.4 \pm 3.8$ & $5.5 \pm 0.7$ & $3.9 \pm 1.4$ & $20.0 \pm 9.1$ & $0.1 \pm 0.1$ \\
\hline & OJP & $225.9 \pm 16.7^{\mathrm{a}}$ & $93.0 \pm 12.1$ & $5.9 \pm 0.9$ & $5.1 \pm 2.4$ & $32.9 \pm 10.3$ & $0.2 \pm 0.1$ \\
\hline
\end{tabular}

Data expressed as mean of triplicate values \pm SEM. Paired t-test was performed to determine difference between OJ and OJP

$O J$ orange juice without pulp; $O J P$ orange juice with pulp

${ }^{\text {a }}$ Significantly different from OJ, $p<0.05$ 
The volume of orange juice used in the models was proportional to the ingestion of $250 \mathrm{ml}$ juice [30]. The model of the upper GI digestion was adapted from Gil-Izquierdo [[31]; supplementary file]. This model has many similarities to the INFOGEST model [32] but there are some variations. There was no saliva phase as the test food is a liquid, and there was no phospholipid in the gastric phase. The gastric phase ran for $1 \mathrm{~h}$, not $2 \mathrm{~h}$ as for the INFOGEST model, and at $\mathrm{pH} 2$ rather than $\mathrm{pH}$ 3. The small intestinal phase was incubated for $4 \mathrm{~h}$, not $2 \mathrm{~h}$. This reflects the liquid nature of our test meal and time required for arrival of the food in the large intestine, which is mimicked by the fermentation model (phase three in our study). Pancreatin and bile extract were included, as suggested by INFOGEST (see supplementary material for additional details). The GI digestion was conducted in triplicate and after digestion the resultant fluid was dialysed (MW cut off $0.1-$ $0.5 \mathrm{kDa}$, Sigma Poole, UK) to remove sugars, dextrins, fatty acids and peptides normally absorbed in the small intestine. Flavonoids would remain (Hesperidin MW 610, Narirutin MW 580). Dialysed samples were freeze-dried (Edwards Micro Modulyo Crawley UK) before transferring to the fermentation model. Samples for the evaluation of stability / release of hesperidin and narirutin from orange juice during digestion were not dialysed.

\section{In Vitro Fermentation Model with Human Colonic Bacteria}

Faecal samples were obtained from six healthy Caucasian volunteers (four women and two men, $23 \pm 2.6$ years, $67 \pm$ $12.5 \mathrm{~kg}$, BMI $22.5 \pm 2.3$ ) who were non-smokers, had a normal diet, no digestive diseases, no food allergies, and did not receive antibiotics for six months prior to recruitment. Volunteers followed a low-polyphenol diet for two days, avoiding fruits, vegetables, tea, coffee, wine and high fibre foods before providing a faecal sample. The model of colonic fermentation was adapted from Jaganath et al. [33].

\section{Analysis of Hesperidin, Hesperetin, Narirutin and Naringenin in Orange Juice, Digesta and Fermented Samples}

Extraction of OJ and OJP A liquid-liquid method was used to extract hesperidin and narirutin from orange juice (see supplementary material for additional details).

\section{Extraction of the Gastric Digesta and the Fermented Samples} A liquid-liquid method was used to extract hesperidin and narirutin from the gastric digesta, and hesperidin, narirutin, hesperetin and naringenin from the fermented samples (see supplementary material for additional details).

\section{Analysis of Hesperidin, Hesperetin, Narirutin and Naringenin by HPLC-PDA}

Analysis of hesperidin, hesperetin, narirutin and naringenin was performed as described by Pereira-Caro et al. [11] (see supplementary material for additional details).

\section{Extraction and Derivatisation of Phenolic Acids in Fermented Samples}

Phenolic acid extraction, derivatisation and analysis were performed as described by Combet et al. [34] (see supplementary material for additional details).

\section{Analysis of Phenolic Acids in Fermented Samples by GC-MS}

To analyse phenolic acids in fermented samples, we used a GCMS method (see supplementary material for additional details).

\section{Statistical Analyses}

All statistical analyses were performed using SPSS statistics software (SPSS version 22, IBM Corporation, Somers, USA). Data were assessed for normality of distribution using the Anderson-Darling test. Data were expressed as mean values \pm SEM. Paired $t$-tests or repeated measures ANOVA with Tukey post hoc tests were used to determine significant differences as $p<0.05$. The in vitro gastrointestinal digestion phase was conducted as $2 \times 3$ and the fermentation with human colonic bacteria was conducted as $2 \times 6$.

\section{Results and Discussion}

\section{Flavanone Content of Orange Juices}

The total content of hesperidin and narirutin in six brands of shop-bought orange juice ranged from 21.3 to $46.0 \mathrm{mg} / 100 \mathrm{ml}$ and there was no significant difference in hesperidin and narirutin between OJ and OJP $(20 \pm 9.1 \mathrm{mg} / 100 \mathrm{ml}$ vs. $32.9 \pm 10.3 \mathrm{mg} / 100 \mathrm{ml} ; 3.9 \pm 1.4 \mathrm{mg} / 100 \mathrm{ml}$ vs. $5.1 \pm$ $2.4 \mathrm{mg} / 100 \mathrm{ml}$ ). Overall, the OJP had higher total phenolic compounds than OJ $\left(225.9 \pm 7.5 \mu \mathrm{g} \mathrm{GAE} \mathrm{ml}^{-1}\right.$ vs. $208.4 \pm 6.1 \mu \mathrm{g}$ $\mathrm{GAE} \mathrm{ml}^{-1}$ ) (Table 1). This may be due to non-flavanone compounds such as flavanols, flavones and phenolic acids [34]. There was no difference between OJ and OJP for all other variables. The fibre content ranged from 0.1 to $0.3 \mathrm{~g} 100 \mathrm{ml}$, and was similar between smooth OJ and OJP (Table 1). The fibre content of each juice was measured only once, but the low values obtained were similar between brands and with the declared fibre content by the manufacturers. The pulp has been suggested to be rich in flavonoids [3]; however, in this study, 
there was little impact of the inclusion of pulp on the extractable flavanone content in these shop-bought juices. Pellet weight after centrifugation of the OJP juices in this study differed by 2-3\% total juice compared to OJ. This is in contrast to the $33 \%$ content for freshly squeezed oranges. In Rangel-Huerta's study [3], $5.5 \mathrm{~g}$ of pulp containing $4.5 \mathrm{~g}$ fibre was added to $500 \mathrm{ml}$ orange juice and more than doubled the amount of flavanones over their standard juice. This is 20 times the dietary fibre in the shopbought juices used in this study. Thus the lack of effect of OJP on flavanone content may be due to the low levels of pulp in these shop-bought juices. The amount of pulp added is not declared.

\section{Impact of In Vitro GI Digestion on Orange Juice Hesperidin and Narirutin}

In the gastric phase model, hesperidin was 1.3 and 1.2 fold higher in the simulated gastric fluid (at beginning and after $1 \mathrm{~h}$ ) with OJP than with OJ with no change in the narirutin content (Table 2). After small intestinal digestion, the recovery of hesperidin was significantly higher in OJ than OJP (89 \pm $6 \%$ and $68 \pm 3 \%$ of original amount) and the narirutin recovery was $55 \pm 1 \%$ and $57 \pm 4 \%$ respectively (Table 2 ).

Tagliazucchi et al. reported that polyphenols (mainly anthocyanins) in grapes decreased by $44 \%$ when transiting from an acidic gastric model to the alkaline small intestinal in vitro digestion model [35]. Another study reported that gastric digestion reduced naringenin, caffeic acid, ferulic acid, $p$ coumaric acid, and 4-hydroxybenzoic acid by 5-36\%, but increased chlorogenic acid, sinapic acid, rutin and (+)-catechin by $5-58 \%$, rather than hesperidin and quercetin in a blended fruit juice containing orange, kiwi, pineapple and mango [36]. In our study, hesperidin was higher in the gastric digesta of OJ compared to OJP, and less hesperidin was recovered from the small intestine model digesta with OJP compared with OJ (even though hesperidin content was similar in the two juice types). This suggests that hesperidin from orange juice with pulp was not as stable in the gastric phase.

Previous in vitro studies have found transformation of orange juice flavanone into chalcone under gastrointestinal conditions [31]. Although hesperidin content was not significantly different between orange juices, after upper GI digestion, recovery of hesperidin was higher in OJ than OJP (Table 2), which may be related to transformation or precipitation of hesperidin. In addition, pulp affected the reduction in hesperidin when transferring from the gastric to alkaline intestinal model in the present study.

\section{Changes in Total Phenolic Content and Antioxidant Capacity during GI Digestion In Vitro}

At $0 \mathrm{~h}$ in the upper GI digestion model, OJ had 1.6 fold higher antioxidant capacity compared with OJP despite a lower hesperidin content. The antioxidant capacity in orange juice is not dependent just on hesperidin or flavanones and there may be food matrix effects [37]. After the upper GI digestion, the total phenolic content was17.2 $\pm 7.2 \mathrm{mg}$ GAE from $40 \mathrm{ml}$ of OJ and $18.5 \pm 1.6 \mathrm{mg} \mathrm{GAE}$ from $40 \mathrm{ml}$ of OJP (Table 2).

Cilla et al. [38] reported that the total phenolic content of fruit beverages was reduced by $47 \%$ during in vitro GI digestion, which is consistent with our findings where we saw a reduction of total phenolic content of 31 and $36 \%$, respectively in OJ and OJP after the upper GI digestion. The pulp could contain small amounts of protein, fat and ash [39], and connective tissues which may influence the phenolic contents during the GI digestion. The effects of these matrices during the GI digestion should be investigated further.

Furthermore, the higher total phenol content in OJP might indicate that addition of pulp increases release of total phenols under upper GI conditions, even though the pulp does not contain much fibre. In addition, the antioxidant capacity decreased respectively by 56 and $42 \%$ in OJ and OJP. Alexandropoulou et al. [40] investigated effects of protein and iron on the antioxidant capacity of green tea under conditions of digestion in vitro. As in the present study, the reduction of antioxidant capacity may be due to the interactions between antioxidants and compounds in the upper GI digestion system, but was not affected by the pulp. The mechanism should be further studied.

\section{Degradation of Hesperidin and Narirutin during Colonic Fermentation In Vitro}

After $24 \mathrm{~h}$ fermentation, total phenolic contents of the fermentation fluid was similar between OJ and OJP ( $4.5 \pm 0.8$ vs. 4.9 $\pm 1.0 \mathrm{mM}$ GAE) (Table 3). Percentages of degradation of hesperidin and narirutin were similar after $24 \mathrm{~h}$ fermentation by gut bacteria. There was no difference in production of hesperetin and naringenin from OJ and OJP (Table 3). This suggests that the pulp had no impact on degradation of orange juice flavanone by gut bacteria. Hesperidin was marginally higher by $14.9 \mu \mathrm{M}$ in the incubation with digested OJP compared with OJ at $2 \mathrm{~h}$ (Table 3). It may be due to increased release of hesperidin from the pulp under upper GI conditions or complexes of flavanone binding to pulp under GI conditions.

\section{Production of Phenolic Acids during Colonic Fermentation In Vitro}

Five phenolic acids (4-hydroxybenzoic acid, 4hydroxyphenylacetic acid, 4-hydrophenylpropionic acid, dihydroferulic acid and 3,4-dihydroxyphenylpropionic acid) was derived from metabolism of orange juices by 


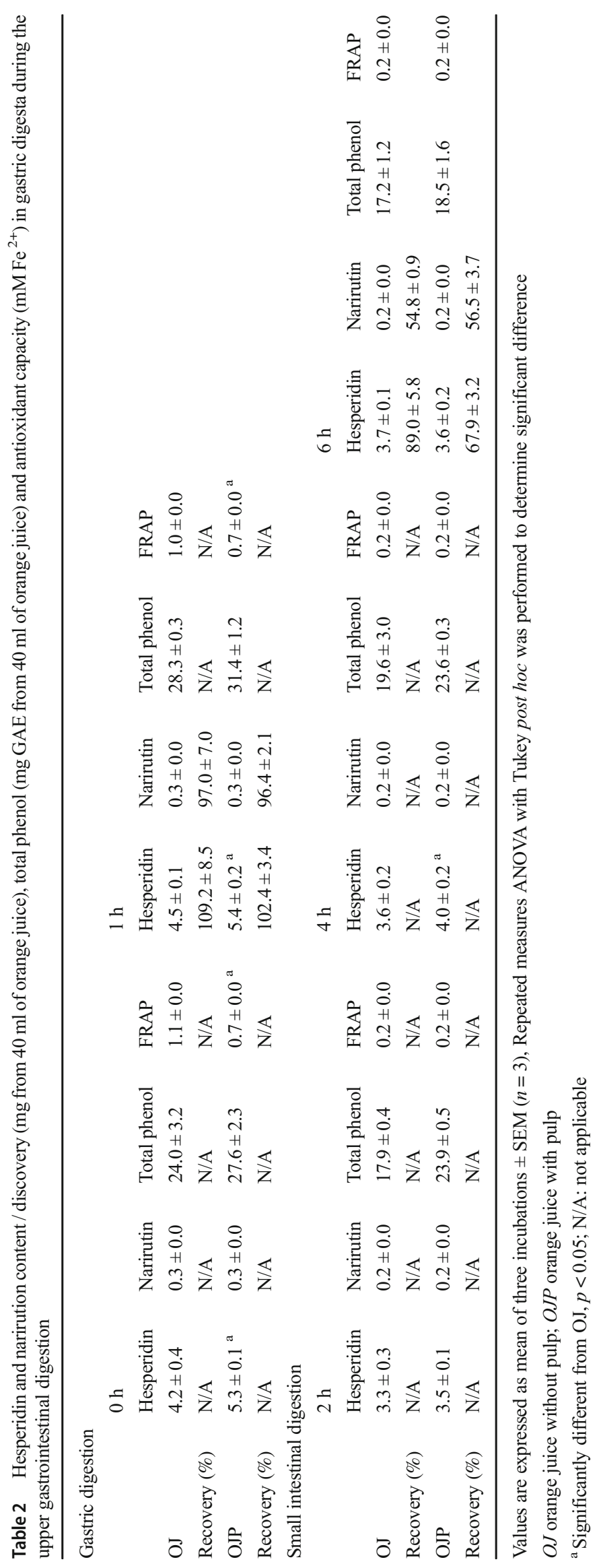


Table 3 Narirutin, hesperidin, naringenin and hesperetin $(\mu \mathrm{M})$, total phenols (mM GAE) in cultures of orange juices during in vitro fermentation with human faecal bacteria

\begin{tabular}{lllllll}
\hline & & Narirutin & Hesperidin & Naringenin & Hesperetin & Total phenol \\
\hline $0 \mathrm{~h}$ & OJ & $2.7 \pm 0.6$ & $68.4 \pm 14.1$ & $1.1 \pm 0.4$ & $0.7 \pm 0.3$ & $5.3 \pm 0.2$ \\
& OJP & $3.8 \pm 0.6$ & $103.1 \pm 9.8$ & $1.5 \pm 0.5$ & $0.9 \pm 0.1$ & $4.6 \pm 0.7$ \\
& OJ & $2.5 \pm 0.7$ & $75.5 \pm 9.0$ & $3.0 \pm 0.5$ & $2.1 \pm 0.5$ & $5.1 \pm 0.4$ \\
& OJP & $2.8 \pm 0.6$ & $90.4 \pm 9.5^{*}$ & $2.7 \pm 0.8$ & $2.3 \pm 0.3$ & $5.6 \pm 0.2$ \\
& OJ & $2.4 \pm 0.7$ & $73.9 \pm 8.6$ & $3.3 \pm 0.9$ & $1.9 \pm 0.9$ & $4.9 \pm 0.7$ \\
$6 \mathrm{~h}$ & OJP & $2.7 \pm 0.6$ & $84.9 \pm 12.7$ & $4.1 \pm 1.0$ & $4.5 \pm 0.4$ & $5.0 \pm 0.8$ \\
& OJ & $2.3 \pm 0.7$ & $68.9 \pm 13.0$ & $3.8 \pm 1.1$ & $3.6 \pm 1.1$ & $5.2 \pm 0.4$ \\
$24 \mathrm{~h}$ & OJP & $2.0 \pm 0.5$ & $78.4 \pm 14.8$ & $3.1 \pm 0.7$ & $3.6 \pm 0.4$ & $5.5 \pm 0.4$ \\
& OJ & $1.4 \pm 0.5$ & $42.9 \pm 12.4$ & $3.7 \pm 0.9$ & $4.6 \pm 1.9$ & $4.5 \pm 0.8$ \\
& OJP & $1.4 \pm 0.4$ & $51.7 \pm 19.3$ & $3.6 \pm 1.0$ & $5.1 \pm 1.8$ & $4.9 \pm 1.0$ \\
\hline
\end{tabular}

Data expressed as mean of six fermentations \pm SEM $(n=6)$, Repeated measures ANOVA with Tukey post-hoc was performed

$O J$ orange juice without pulp; OJP orange juice with pulp

a Significantly different from OJ, $p<0.05$ gut bacteria (Fig. 1). The total amount of five phenolic acids was similar between OJ and OJP during simulated colonic fermentation $(40.0 \pm 11.4 \mu \mathrm{M}$ and $48.0 \pm 8.9 \mu \mathrm{M})$
(Fig. 1). This indicated that adding pulp did not influence degradation of hesperidin and narirutin in commercial orange juice.
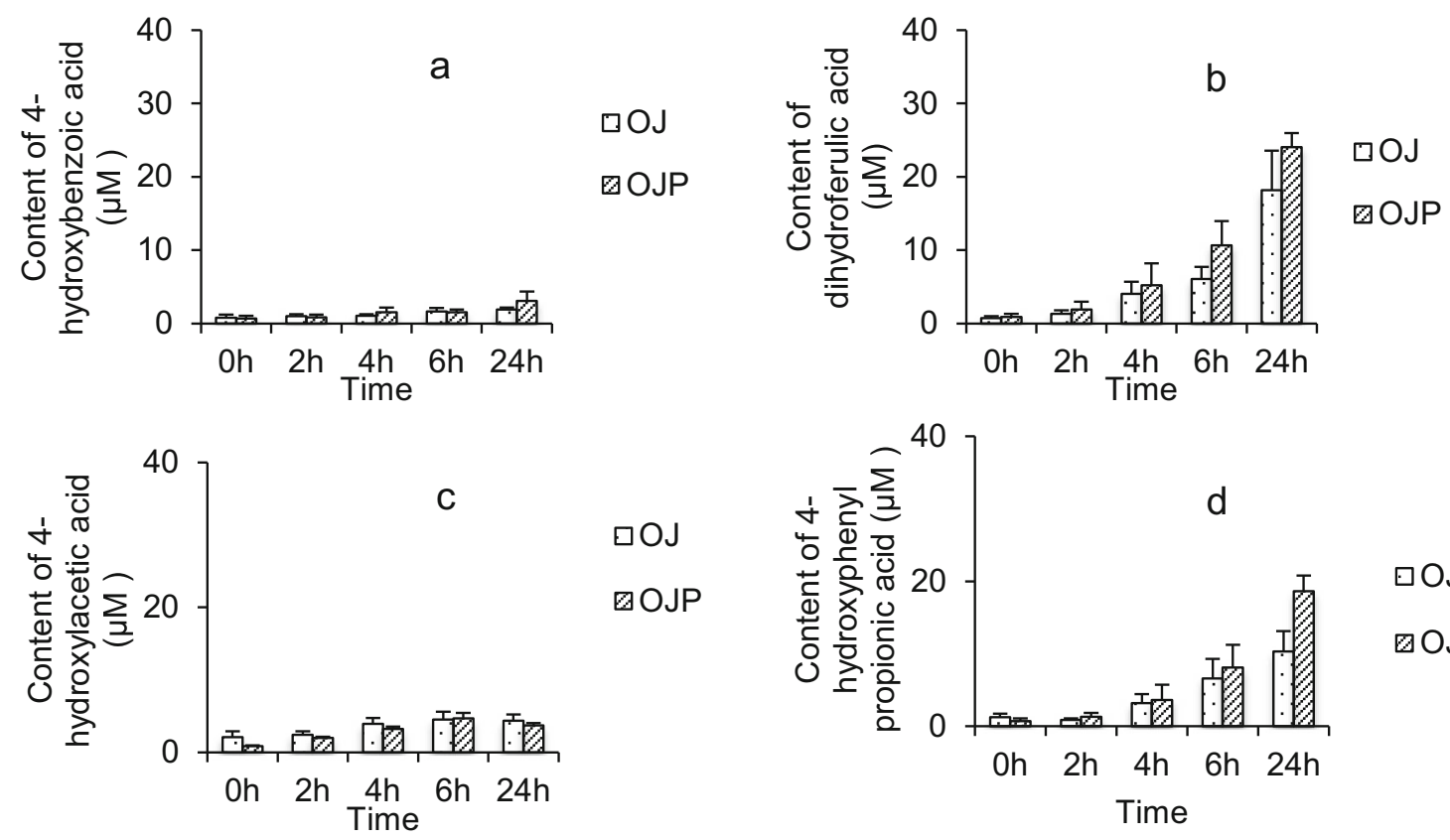

$\square O J$

๑ OJP
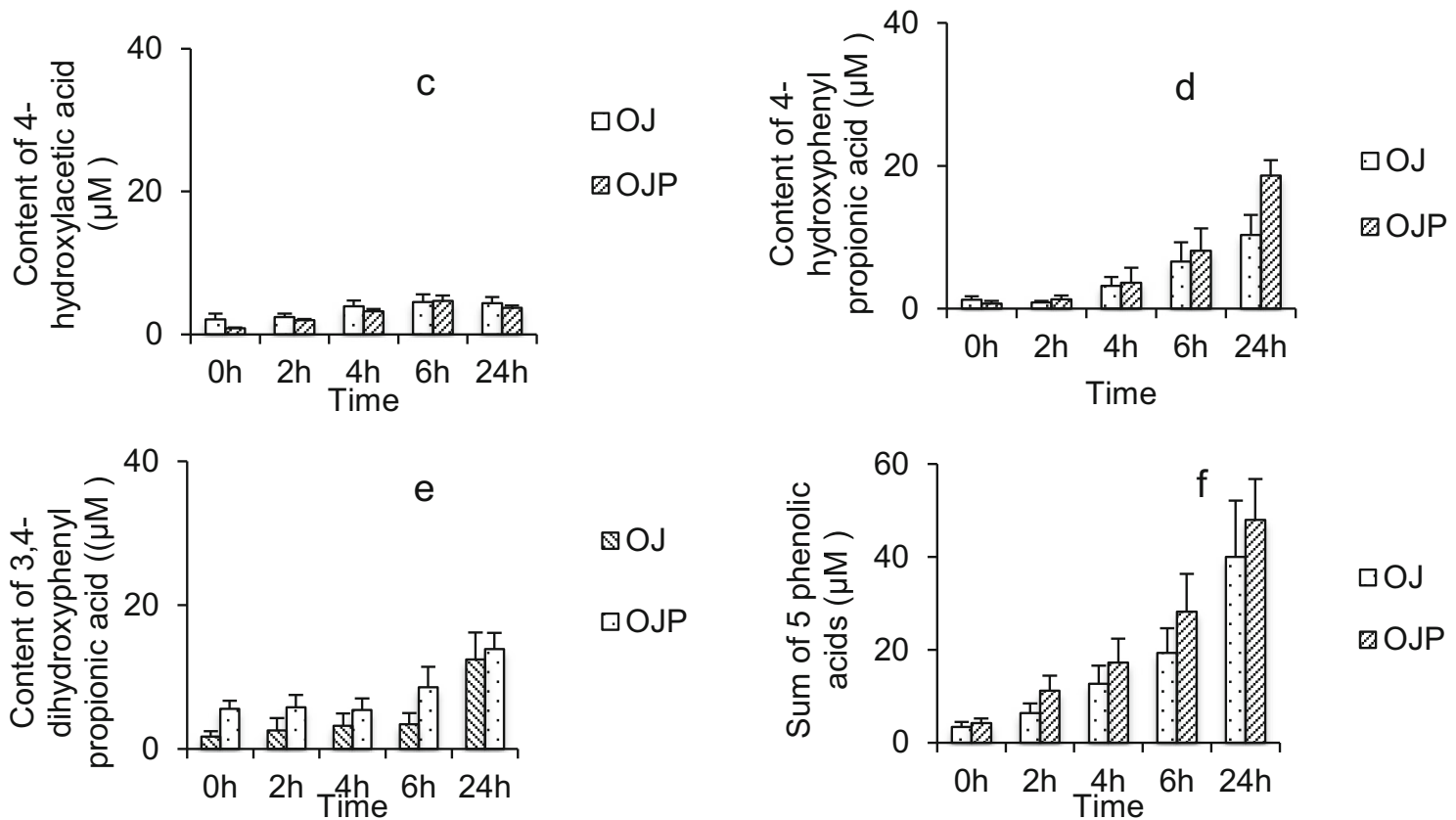

Fig. 1 Contents of 4-hydroxybenzoic acid (a), dihydroferulic acid (b), 4hydroxyphenylacetic acid (c), 4-hydrophenylpropionic acid (d), 3,4dihydroxyphenylpropionic acid (e) and sum of these five phenolic acids

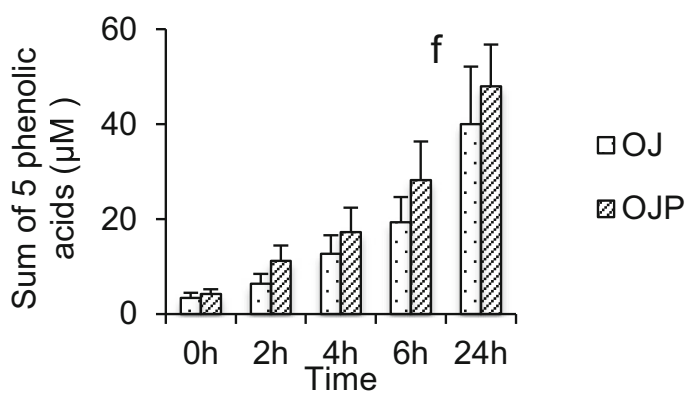

(f) $(\mu \mathrm{M})$ during $24 \mathrm{~h}$ fermentation with gut bacteria. Data expressed as mean values $\pm \operatorname{SEM}(n=6)$ 


\section{Conclusions}

Orange juice is considered to be a health-promoting beverage, especially with pulp. However, in this study, the fibre content was similar with and without pulp. The pulp increased recovery of flavanone during the upper GI digestion, but did not affect degradation of flavanone and production of phenolic acids over $24 \mathrm{~h}$ of colonic fermentation, although at $2 \mathrm{~h}$ there was a higher level of hesperidin in OJP. The orange juices highly enriched with pulp may have higher phenolic content than pulp-free juices. However, our study highlights that those orange juices with added pulp on sale in UK supermarkets have no greater impact on gut metabolism than juice without pulp. To improve consumer understanding of any potential health benefits of orange juice with pulp, it should be clear how much pulp is added to the juice and if this is enough to affect gut metabolism of hesperidin and narirutin, which should be further studied. More information is needed to enable informed choice for consumers if the health properties of polyphenols are considered to be of importance.

Acknowledgements This study was funded by a scholarship from the Chinese Scholarship Council and the University of Glasgow.

\section{Compliance with Ethical Standards}

Conflict of Interest The authors declare that they have no conflict of interest.

Open Access This article is distributed under the terms of the Creative Commons Attribution 4.0 International License (http:// creativecommons.org/licenses/by/4.0/), which permits unrestricted use, distribution, and reproduction in any medium, provided you give appropriate credit to the original author(s) and the source, provide a link to the Creative Commons license, and indicate if changes were made.

\section{References}

1. Fusco R, Cirmi S, Gugliandolo E, Di Paola R, Cuzzocrea S, Navarra M (2017) A flavonoid-rich extract of orange juice reduced oxidative stress in an experimental model of inflammatory bowel disease. J Funct Foods 30:168-178

2. Coelho RC, Hermsdorff HH, Bressan J (2013) Anti-inflammatory properties of orange juice: possible favorable molecular and metabolic effects. Plant Foods Hum Nutr 68:1-10

3. Rangel-Huerta OD, Aguilera CM, Martin MV, Soto MJ, Rico MC, Vallejo F et al. (2015) Normal or high polyphenol concentration in orange juice affects antioxidant activity, blood pressure, and body weight in obese or overweight adults. J Nutr 145:1808-1816

4. Morand C, Dubray C, Milenkovic D, Lioger D, Martin JF, Scalbert A, Mazur A (2011) Hesperidin contributes to the vascular protective effects of orange juice: a randomized crossover study in healthy volunteers. Am J Clin Nutr 93:73-80

5. Chiba H, Uehara M, Wu J, Wang X, Masuyama R, Suzuki K, Kanazawa K, Ishimi Y (2003) Hesperidin, a citrus flavonoid, inhibits bone loss and decreases serum and hepatic lipids in ovariectomized mice. J Nutr 133:1892-1897
6. Kean RJ, Lamport DJ, Dodd GF, Freeman JE, Williams CM, Ellis JA, Butler LT, Spencer JP (2015) Chronic consumption of flavanone-rich orange juice is associated with cognitive benefits: an 8-wk, randomized, double-blind, placebo-controlled trial in healthy older adults. Am J Clin Nutr 101:506-514

7. Neveu V, Perez-Jimenez J, Vos F, Crespy V, Du Chaffaut L, Mennen L, Knox C, Eisner R, Cruz J, Wishart D (2010) Phenolexplorer: an online comprehensive database on polyphenol contents in foods. Database 2010:bap024

8. Bredsdorff L, Nielsen IL, Rasmussen SE, Cornett C, Barron D, Bouisset F, Offord E, Williamson G (2010) Absorption, conjugation and excretion of the flavanones, naringenin and hesperetin from alpha-rhamnosidase-treated orange juice in human subjects. Br J Nutr 103(11):1602-1609

9. Brett GM, Hollands W, Needs PW, Teucher B, Dainty JR, Davis BD, Brodbelt JS, Kroon PA (2009) Absorption, metabolism and excretion of flavanones from single portions of orange fruit and juice and effects of anthropometric variables and contraceptive pill use on flavanone excretion. Br J Nutr 101:664-675

10. Erlund I, Meririnne E, Alfthan G, Aro A (2001) Plasma kinetics and urinary excretion of the flavanones naringenin and hesperetin in humans after ingestion of orange juice and grapefruit juice. J Nutr 131:235-241

11. Pereira-Caro G, Borges G, Van Der Hooft J et al (2014) Orange juice (poly) phenols are highly bioavailable in humans. Am J Clin Nutr 100(5):1378-1384

12. Silveira JQ, Cesar TB, Manthey JA, Baldwin EA, Bai J, Raithore $S$ (2014) Pharmacokinetics of flavanone glycosides after ingestion of single doses of fresh-squeezed orange juice versus commercially processed orange juice in healthy humans. J Agric Food Chem 62:12576-12584

13. Tomás-Navarro M, Vallejo F, Sentandreu E et al (2013) Volunteer stratification is more relevant than technological treatment in orange juice flavanone bioavailability. J Agric Food Chem 62:24-27

14. Vallejo F, Larrosa M, Escudero E, Zafrilla MP, Cerdá B, Boza J, García-Conesa MT, Espín JC, Tomás-Barberán FA (2010) Concentration and solubility of flavanones in orange beverages affect their bioavailability in humans. J Agric Food Chem 58: 6516-6524

15. Manach C, Williamson G, Morand C, Scalbert A, Rémésy C (2005) Bioavailability and bioefficacy of polyphenols in humans. I. Review of 97 bioavailability studies. Am J Clin Nutr 81:230S$242 \mathrm{~S}$

16. Crozier A, Del Rio D, Clifford MN (2010) Bioavailability of dietary flavonoids and phenolic compounds. Mol Asp Med 31:446-467

17. Roowi S, Mullen W, Edwards CA, Crozier A (2009) Yoghurt impacts on the excretion of phenolic acids derived from colonic breakdown of orange juice flavanones in humans. Mol Nutr Food Res 53(S1):S68-S75

18. Selma MV, Espin JC, Tomas-Barberan FA (2009) Interaction between phenolics and gut microbiota: role in human health. J Agric Food Chem 57:6485-6501

19. Aura A-M (2008) Microbial metabolism of dietary phenolic compounds in the colon. Phytochem Rev 7:407-429

20. Winter J, Moore L, Dowell V, Bokkenheuser V (1989) C-ring cleavage of flavonoids by human intestinal bacteria. Appl Environ Microb 55:1203-1208

21. Tzounis X, Vulevic J, Kuhnle GG, George T, Leonczak J, Gibson GR, Kwik-Uribe C, Spencer JP (2008) Flavanol monomer-induced changes to the human faecal microflora. Br J Nutr 99:782-792

22. Larrea MACYK, Martínez Bustos F (2005) Effect of some operational extrusion parameters on the constituents of orange pulp. Food Chem 89:301-308

23. Aschoff JK, Kaufmann S, Kalkan O, Neidhart S, Carle R, Schweiggert RM (2015) In vitro bioaccessibility of carotenoids, flavonoids, and vitamin $\mathrm{C}$ from differently processed oranges and 
orange juices [Citrus sinensis (L.) Osbeck]. J Agric Food Chem 63: 578-587

24. Alharbi MH, Lamport DJ, Dodd GF, Saunders C, Harkness L (2015) Flavonoid-rich orange juice is associated with acute improvements in cognitive function in healthy middle-aged males. Eur J Nutr 55:1-9

25. Pérez-Jiménez J, Serrano J, Tabernero M, Arranz S, Díaz-Rubio ME, García-Diz L, Goñi I, Saura-Calixto F (2009) Bioavailability of phenolic antioxidants associated with dietary fiber: plasma antioxidant capacity after acute and long-term intake in humans. Plant Foods Hum Nutr 64:102-107

26. McCleary BV, DeVries JW, Rader JI, Cohen G, Prosky L (2012) Determination of insoluble, soluble, and total dietary fiber (CODEX definition) by enzymatic-gravimetric method and liquid chromatography: collaborative study. J AOAC Int 95:824-844

27. Chang C-C, Yang M-H, Wen H-M, Chern J-C (2002) Estimation of total flavonoid content in propolis by two complementary colorimetric methods. J Food Drug Anal 10:178-182

28. Singleton V, Rossi JA (1965) Colorimetry of total phenolics with phosphomolybdic-phosphotungstic acid reagents. Am J Enol Viticul 16:144-158

29. Benzie IF, Strain J (1996) The ferric reducing ability of plasma (FRAP) as a measure of "antioxidant power": the FRAP assay. Anal Biochem 239:70-76

30. Mullen W, Archeveque MA, Edwards CA, Matsumoto H, Crozier A (2008) Bioavailability and metabolism of orange juice flavanones in humans: impact of a full-fat yogurt. J Agric Food Chem 56: 11157-11164

31. Gil-Izquierdo A, Gil MI, Tomás-Barberán FA, Ferreres F (2003) Influence of industrial processing on orange juice flavanone solubility and transformation to chalcones under gastrointestinal conditions. J Agric Food Chem 51:3024-3028

32. Minekus M, Alminger M, Alvito P, Ballance S, Bohn T, Bourlieu C, Carriere $\mathrm{F}$ et al (2014) A standardised static in vitro digestion method suitbale for food- an international consensus. Food Funct 5: $1113-1124$
33. Jaganath IB, Mullen W, Lean MEJ, Edwards CA, Crozier A (2009) In vitro catabolism of rutin by human fecal bacteria and the antioxidant capacity of its catabolites. Free Radic Biol Med 47:1180-1189

34. Combet E, Lean ME, Boyle JG, Crozier A, Davidson DF (2011) Dietary flavonols contribute to false-positive elevation of homovanillic acid, a marker of catecholamine-secreting tumors. Clin Chim Acta 412:165-16932

35. Tagliazucchi $\mathrm{D}$, Verzelloni $\mathrm{E}$, Bertolini $\mathrm{D}$, Conte a (2010) In vitro bio-accessibility and antioxidant activity of grape polyphenols. Food Chem 120:599-606

36. Rodríguez-Roque MJ, Rojas-Graü MA, Elez-Martínez P, MartínBelloso O (2014) In vitro bioaccessibility of health-related compounds as affected by the formulation of fruit juice- and milkbased beverages. Food Res Int 62:771-778

37. Ovando-Martínez M, Gámez-Meza N, Molina-Domínguez CC, Hayano-Kanashiro C, Medina-Juárez LA (2018) Simulated gastrointestinal digestion, bioaccessibility and antioxidant capacity of polyphenols from red Chiltepin (Capsicum annuum L. var. glabriusculum) grown in Northwest Mexico. Plant Foods Hum Nutr 73:116-121

38. Cilla A, González-Sarrías A, Tomás-Barberán FA, Espín JC, Barberá R (2009) Availability of polyphenols in fruit beverages subjected to in vitro gastrointestinal digestion and their effects on proliferation, cell-cycle and apoptosis in human colon cancer Caco2 cells. Food Chem 114:813-820

39. Grigelmo-Miguel N, Martín-Belloso O (1998) Characterization of dietary fiber from orange juice extraction. Food Res Int 31:355-361

40. Alexandropoulou I, Komaitis M, Kapsokefalou M (2006) Effects of iron, ascorbate, meat and casein on the antioxidant capacity of green tea under conditions of in vitro digestion. Food Chem 94:359-365

Publisher's Note Springer Nature remains neutral with regard to jurisdictional claims in published maps and institutional affiliations. 